\title{
Calibration of LACIS as a CCN detector and its use in measuring activation and hygroscopic growth of atmospheric aerosol particles
}

\author{
H. Wex, A. Kiselev, M. Ziese, and F. Stratmann \\ Leibniz Institute for Tropospheric Research, Permoser Str. 15, 04318 Leipzig, Germany \\ Received: 8 June 2006 - Published in Atmos. Chem. Phys. Discuss.: 7 July 2006 \\ Revised: 29 September 2006 - Accepted: 3 October 2006 - Published: 6 October 2006
}

\begin{abstract}
A calibration for LACIS (Leipzig Aerosol Cloud Interaction Simulator) for its use as a CCN (cloud condensation nuclei) detector has been developed. For this purpose, sodium chloride and ammonium sulfate particles of known sizes were generated and their grown sizes were detected at the LACIS outlet. From these signals, the effective critical super-saturation was derived as a function of the LACIS wall temperature. With this, LACIS is calibrated for its use as a $\mathrm{CCN}$ detector. The applicability of LACIS for measurements of the droplet activation, and also of the hygroscopic growth of atmospheric aerosol particles was tested. The activation of the urban aerosol particles used in the measurements was found to occur at a critical super-saturation of $0.46 \%$ for particles with a dry diameter of $75 \mathrm{~nm}$, and at $0.42 \%$ for $85 \mathrm{~nm}$, respectively. Hygroscopic growth was measured for atmospheric aerosol particles with dry diameters of 150, 300 and $350 \mathrm{~nm}$ at relative humidities of 98 and $99 \%$, and it was found that the larger dry particles contained a larger soluble volume fraction of about 0.85 , compared to about 0.6 for the $150 \mathrm{~nm}$ particles.
\end{abstract}

\section{Introduction}

In recent years, the research on clouds and their role in the global climate has obtained a still growing attention, due to the large uncertainties of the effects of clouds on climate (IPCC et al., 2001). One of the areas of research is the activation of atmospheric aerosol particles to cloud droplets. The activation depends on the size and also on the chemical composition of the atmospheric aerosol particles, together with thermodynamic and dynamic properties of the atmosphere.

Measurements have been done on the cloud droplet number concentrations directly in the atmosphere (e.g., Hudson et al., 2000; Snider and Brenguier, 2000; among many stud-

Correspondence to: $\mathrm{H}$. Wex

(wex@ tropos.de) ies), or the activation of aerosol particles to droplets was measured in the laboratory on selected substances (e.g., Kumar et al., 2003; Raymond and Pandis, 2002, among many other studies).

It has been tried to derive cloud particle number concentrations based on measurements of the hygroscopic growth of aerosol particles, either in laboratory experiments or for atmospheric aerosol (e.g., Covert et al., 1998; Brechtel and Kreidenweis, 2000a,b; Dusek et al., 2003; Kreidenweis et al., 2005; Koehler et al., 2006). In general, the derivation was more successful for laboratory studies than for those conducted in the real atmosphere. This was explained by the fact that the hygroscopic growth measurements could be done only for relative humidities $(R H \mathrm{~s})$ up to 90 or $95 \%$. Partially soluble substances that only dissolve at higher $R H \mathrm{~s}$, or changes in the surface tension thus would not be captured.

Besides their activation to cloud droplets, also the size, i.e. the equilibrium diameter, of atmospheric aerosol particles at atmospheric relative humidities has been an object of many studies (e.g., Svenningsson et al., 1992, 1997; Zhang et al., 1993; Pitchford and McMurry, 1994; Swietlicki et al., 1999; Busch et al., 2002; Massling et al., 2003); because the hygroscopically grown size of the particles in the atmosphere determines their influence on incoming solar radiation.

LACIS, the Leipzig Aerosol Cloud Interaction Simulator, has been build to examine both, hygroscopic growth and particle activation to cloud droplets (Stratmann et al., 2004). It has been shown, that measurements of the hygroscopic growth are possible with LACIS at $R H$ s up to $99.1 \%$ (Wex et al., 2005). This work now will show the functionality of LACIS as a detector for critical super-saturations of aerosol particles. A calibration of LACIS with sodium chloride and ammonium sulfate will be shown. Based on this calibration, measurements of the critical super-saturations of size segregated atmospheric aerosol particles were performed. Also the functionality of LACIS for measuring hygroscopic growth of atmospheric aerosol particles is demonstrated.

Published by Copernicus GmbH on behalf of the European Geosciences Union. 


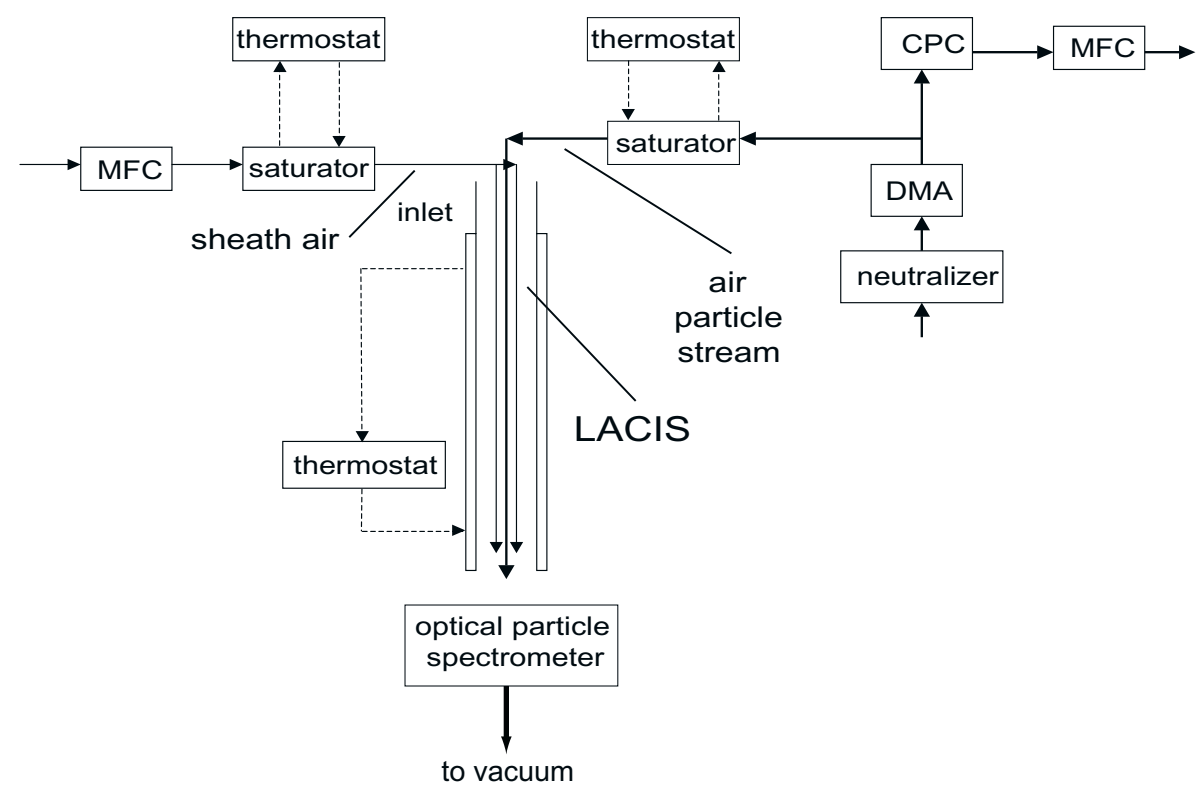

Fig. 1. A sketch of the set-up.

\section{Experimental setup}

In the present state LACIS is a laminar flow tube with a length of $1 \mathrm{~m}$ and with thermostated walls. It has been described in detail before (Stratmann et al., 2004; Wex et al., 2005). A draft of the setup is shown in Fig. 1. Inside the flow tube, the water-vapor-saturation can be controlled by two measures: (1) by humidifying aerosol and sheath air, before they pass through the flow tube, so they have a well defined dew point temperature, and (2) by controlling the wall temperature.

There are two modes of operating LACIS: First, a stable relative humidity $(R H)$ can be held inside LACIS, with $R H \mathrm{~s}$ from almost zero to above $99 \%$ (Wex et al., 2005). For this, the dew point temperature of aerosol and sheath air have to be lower than the wall temperature of the flow tube. During this mode of operation aerosol particles grow to their equilibrium diameter during the passage of the first $20-30 \mathrm{~cm}$ into the flow tube if they are hygroscopic. The $R H$ in the flow tube is derived based on the adjusted dew point and the wall temperature. The agreement of the thus derived $R H$ with the hygroscopic growth of known salts was shown in Wex et al. (2005). For the second mode LACIS can be operated at a slight water vapor super-saturation (Stratmann et al., 2004). For this, the dew point temperatures have to be larger than the wall temperature of LACIS. The highest super-saturation possible is in the range of several percent. The smallest super-saturation used in this study was $0.2 \%$. The maximum super-saturation is reached at about $20 \mathrm{~cm}$ into the flow tube. Particles with critical super-saturations $\left(\mathrm{S}_{\text {crit }}\right)$ below the super-saturation adjusted in LACIS activate and grow while passing through the flow tube, following kinetic growth laws, and their resulting droplet size is measured at the LACIS outlet. A calibration of the obtained critical super-saturations versus the wall temperature is introduced in this work.

For the calibration of LACIS super-saturations, aerosol particles of $\mathrm{NaCl}$ or of $\left(\mathrm{NH}_{4}\right)_{2} \mathrm{SO}_{4}$ were produced by atomizing a solution of $0.1 \mathrm{~g}$ salt per liter double de-ionized water (atomizer: TSI 3075, TSI Inc., St. Paul, Minnesota, USA). The resulting aerosol particles were dried in a diffusion dryer. A DMA (Differential Mobility Analyzer, Knutson and Whitby (1975), type "Vienna medium") was used to select a dry particle size. When using $\mathrm{NaCl}$, a shape factor of 1.08 (Kelly and McMurry, 1992) was used when determining the dry particle size selected by the DMA. Number concentrations of the quasi monodisperse aerosol after the DMA were determined with a CPC (TSI 3010, TSI Inc., St. Paul, Minnesota, USA), and were kept at $400-600 \mathrm{~cm}^{-3}$ with a dilution system up stream of the DMA.

In the flow tube, the aerosol was confined by sheath air in a narrow beam (about $2 \mathrm{~mm}$ in diameter) at the center axis of LACIS, so the thermodynamic conditions are nearly constant across the particle beam. The residence time in LACIS is about $2 \mathrm{~s}$. The flow velocity was chosen so that buoyancy effects were avoided.

At the outlet of the flow tube, the number concentration and size of the humidified particles was measured with an optical particle spectrometer that has been designed and built especially for LACIS (for details see Kiselev et al., 2005). A xenon-arc lamp provided white light for the measurement. The measurement was performed through a slit in the LACIS flow-tube. The scattered light was collected by two elliptical 


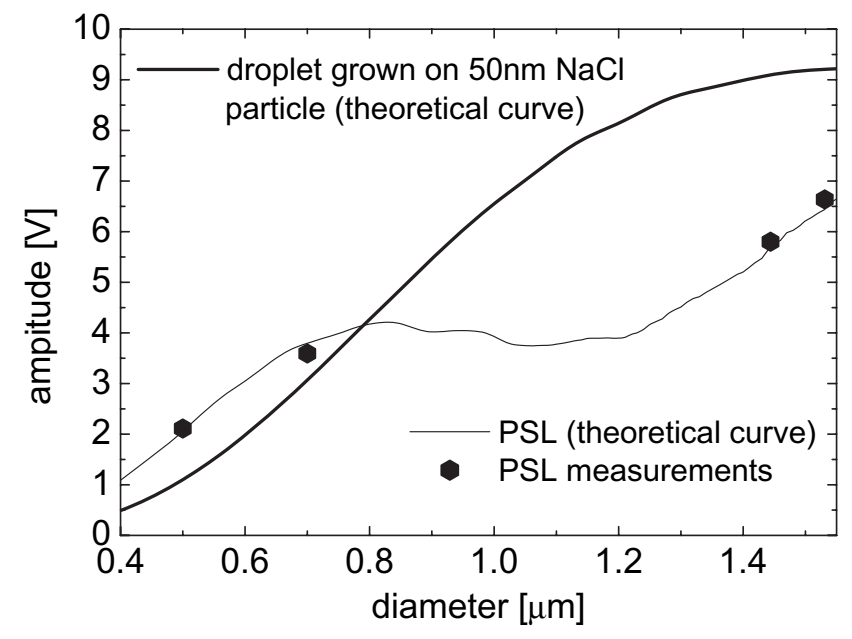

Fig. 2. The response curves for the conversion of the amplitudes of the signals measured with the optical particle spectrometer to droplet diameters, for PSL particles and for droplets grown on $\mathrm{NaCl}$ particles with a dry diameter of $50 \mathrm{~nm}$.

mirrors and led into two photo-multipliers. The response curve of the instrument was modeled and aligned through calibration with PSL particles. Figure 2 shows the measured PSL signals, the modeled PSL response curve, and an exemplary response curve for $\mathrm{NaCl}$ particles with a dry diameter of $50 \mathrm{~nm}$. Response curves calculated for solutions account for changes in the particle refractive index with changing particle concentration (see Kiselev et al., 2005). For the experiment introduced in this work, the smallest detectable size was about $250 \mathrm{~nm}$ when the full intensity of the light source of the optical particle spectrometer was used.

In addition to measurements, simulations of the growth of the aerosol particles inside the flow tube were made. The simulations were done with a computational fluid dynamics code, FLUENT (Fluent , 2003), and the FPM (Fine Particle Model, Wilck et al., 2002).

\section{Calibration}

For the determination of the LACIS super-saturation, calibrations were done, using $\mathrm{NaCl}$ particles with a dry diameter of $50 \mathrm{~nm}$ and $\left(\mathrm{NH}_{4}\right)_{2} \mathrm{SO}_{4}$ particles with varying dry diameters in the range from 30 to $150 \mathrm{~nm}$. For all experiments in the super-saturation mode of LACIS, the dew point temperature of aerosol and sheath air was set to $19^{\circ} \mathrm{C}$.

For a first set of measurements, $50 \mathrm{~nm} \mathrm{NaCl}$ particles were sent through LACIS and their grown size was detected at the LACIS outlet. $\mathrm{T}_{\text {wall }}$ was varied from $11.5^{\circ} \mathrm{C}$ to $12.5^{\circ} \mathrm{C}$ in temperature steps of $0.1 \mathrm{~K}$. Figure 3 exemplarily shows the raw signal measured with the optical particle spectrometer for the measurement at $11.8^{\circ} \mathrm{C}$. The response curve valid for the conversion of the measured amplitudes to diameters has

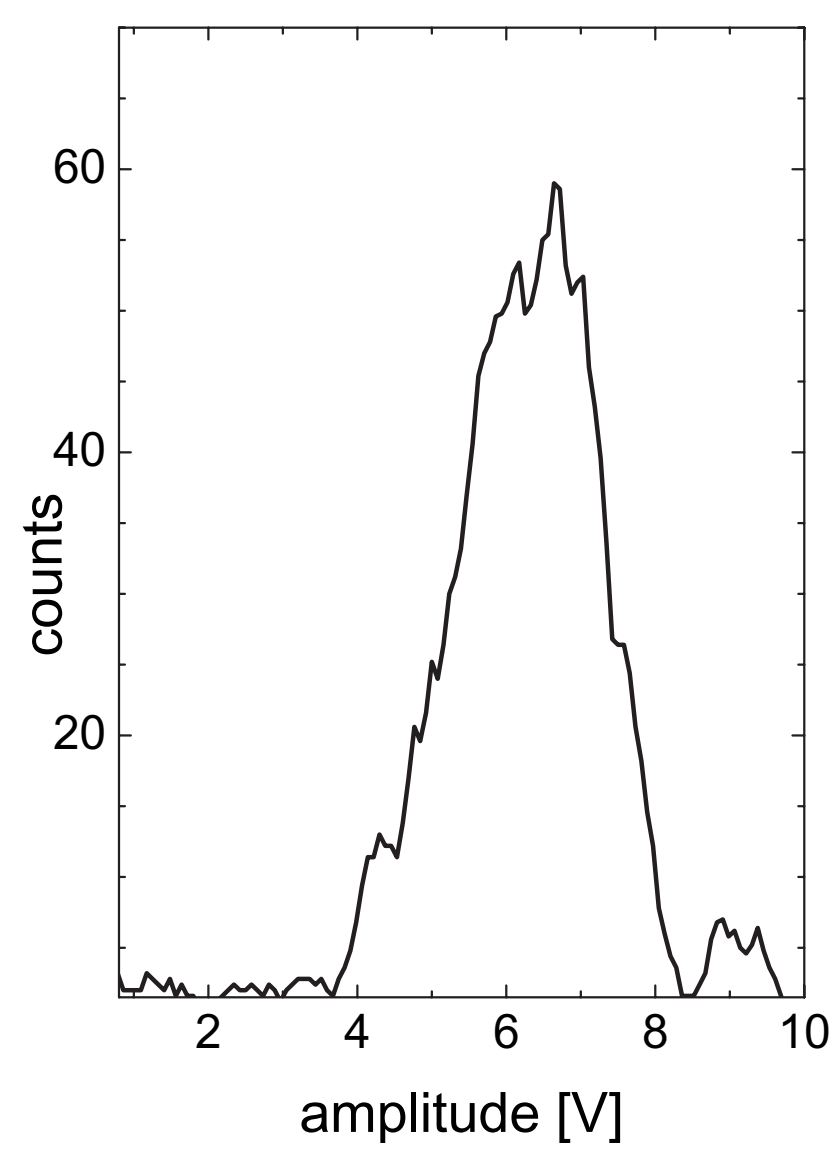

Fig. 3. An exemplary signal measured with the optical particle spectrometer, for the measurement at $11.8^{\circ} \mathrm{C}$. Doubly charged particles that passed the DMA appear at a pulse height of about $9 \mathrm{~V}$, clearly distinguished from the main peak.

been shown earlier (see Fig. 2). Signals from doubly charged particles selected by the DMA clearly can be distinguished from the majority of the singly charged particles, as can be seen in Fig. 3, where the larger doubly charged particles appear at a pulse height of about $9 \mathrm{~V}$, in a peak clearly distinguished from the main peak of the droplets grown on the singly charged particles.

Figure 4 shows the complete results for the measurements with varying $T_{\text {wall }}$. Given are the sizes of the grown droplets measured at the LACIS outlet versus $T_{\text {wall }}$. The values on display are the average of three to five measurements, done on different days. The day-to-day variability of the measured grown sizes was smaller than $+/-4 \%$, except for the measurement at the critical super-saturation, where it was $14 \%$. Fluent/FPM was used to model the sizes of the grown particles for the conditions in the flow tube used during the measurements, and the course of these simulations also can be seen in Fig. 4.

Figure 4 shows a curve with two clearly distinct parts. For $\mathrm{T}_{\text {wall }}$ between $12.5^{\circ} \mathrm{C}$ and $12.1^{\circ} \mathrm{C}$, the grown size of 


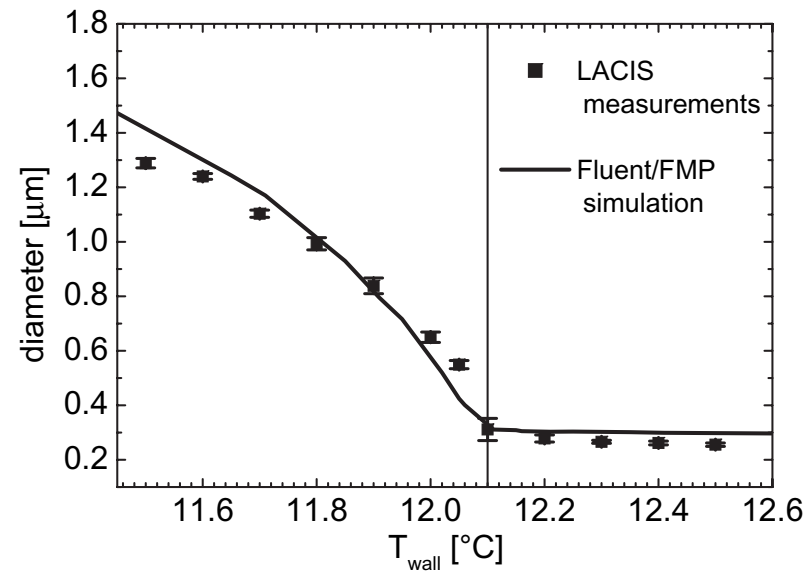

Fig. 4. Measured and simulated droplet diameters at the LACIS outlet for varying wall temperatures, for $\mathrm{NaCl}$ particles with a dry diameter of $50 \mathrm{~nm}$.

the particles only increases slightly with decreasing $\mathrm{T}_{\text {wall }}$, whereas it increases sharply for $\mathrm{T}_{\text {wall }}$ below $12.1^{\circ} \mathrm{C}$. Above $12.1^{\circ} \mathrm{C}$, the super-saturation in LACIS does not exceed the critical super-saturation needed for the activation of the $50 \mathrm{~nm} \mathrm{NaCl}$ particles. At about $12.1^{\circ} \mathrm{C}$, the critical supersaturation is reached and the particles activate and grow dynamically until they reach the optical detector. For $\mathrm{T}_{\text {wall }}$ decreasing further, i.e. for increasing super-saturations, this dynamic growth leads to an increase in the grown particles size at the LACIS outlet.

Critical super-saturations for aerosol particles can be calculated via Köhler theory. A simple form of the Köhler equation was used for this work (described in Wex et al., 2005), assuming the surface tension of water as given in Low (1969), and using a constant van't Hoff factor of 2 for $\mathrm{NaCl}$. For $\left(\mathrm{NH}_{4}\right)_{2} \mathrm{SO}_{4}$, a variable osmotic coefficient was used, as described in Wex et al. (2005). With this, the critical supersaturation for the $50 \mathrm{~nm} \mathrm{NaCl}$ particles is $0.3 \%$. Thus, the effective super-saturation in LACIS at a $\mathrm{T}_{\text {wall }}$ of $12.1^{\circ} \mathrm{C}$ is now known to be $0.3 \%$. Similar measurements were repeated for $\mathrm{NaCl}$ particles with 35,45 , and $55 \mathrm{~nm}$ dry diameter, for which the kink in the curves were found at $\mathrm{T}_{\text {wall }}$ of 11.7, 11.9 and $12.2^{\circ} \mathrm{C}$, respectively (see Fig. 5).

Measurements were also done for $\left(\mathrm{NH}_{4}\right)_{2} \mathrm{SO}_{4}$ particles. Here, for each measurement, $\mathrm{T}_{\text {wall }}$ was kept at a fixed value while the size of the particles was varied between 25 and $150 \mathrm{~nm}$. Growth curves similar to Fig. 4 were obtained, with the sharp increase in grown size towards larger diameters. The kink in the curve here gives the diameter above which particles were activated, i.e. it gives again the effective supersaturation for the respective $T_{\text {wall }}$. Measurements were repeated up to 4 times for the same conditions. The resulting relation between $T_{\text {wall }}$ and effective super-saturation is shown in Fig. 5, including the results for $\mathrm{NaCl}$ as well as

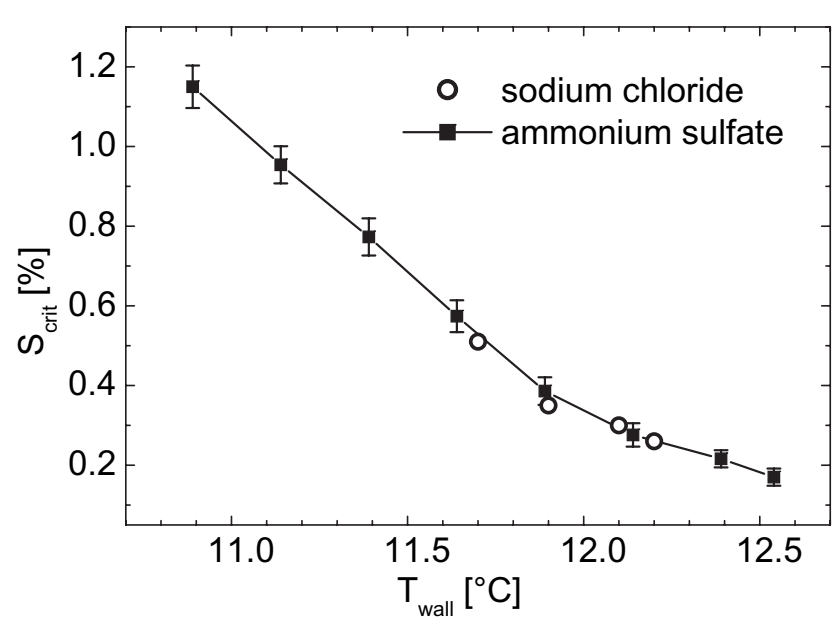

Fig. 5. LACIS calibration curve for the relation between $T_{\text {wall }}$ and critical super-saturation.

for $\left(\mathrm{NH}_{4}\right)_{2} \mathrm{SO}_{4}$ particles. When more than one measurement was available, the values were averaged. The deviations between these separate measurements depend on uncertainties in different parameters, as there are the sizing with the DMA, the dew point temperatures and $\mathrm{T}_{\text {wall }}$, and uncertainties of the optical particle spectrometer as discussed in Kiselev et al. (2005). However, these deviations between up to 4 separate measurements were found to be below $0.03 \%$ (one standard deviation; value given as absolute value in terms of measured critical super-saturation), being smaller for smaller supersaturations. This deviation includes the day-to-day variability of LACIS, i.e. the different measurement uncertainties of the set-up. The measurements for $\left(\mathrm{NH}_{4}\right)_{2} \mathrm{SO}_{4}$ and for $\mathrm{NaCl}$ agree within these measurement uncertainties. With this procedure, the LACIS flow tube now is calibrated for measurements at super-saturated conditions.

\section{Measurements of activation and hygroscopic growth of atmospheric aerosol particles}

To test the applicability of LACIS to measure atmospheric aerosol samples, atmospheric aerosol particles of selected sizes were measured with LACIS under both, super- and subsaturated conditions. The measurements were performed at the Institute for Tropospheric Research in Leipzig, Germany, sampling urban aerosol during a time with prevailing high pressure conditions and without precipitation, during March and April 2005.

\subsection{Activation}

Urban atmospheric aerosol particles were exposed to supersaturation in LACIS to measure their behavior as CCN (cloud condensation nuclei) and their dynamic growth. 


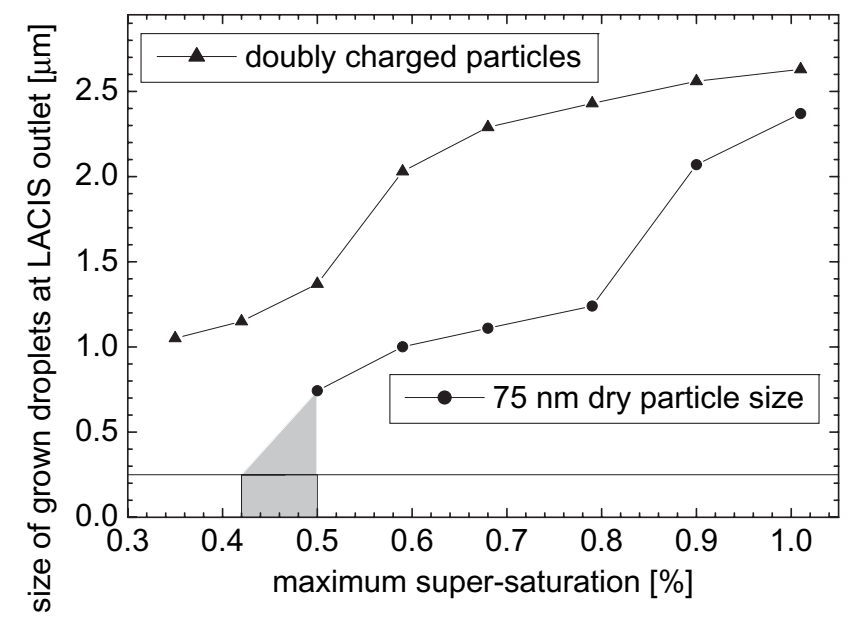

Fig. 6. The size of the droplets grown on $75 \mathrm{~nm}$ (and the respective doubly charged $111 \mathrm{~nm}$ ) urban atmospheric aerosol particles for different super-saturations in LACIS.

Measurements were done on 12 and 14 April 2005. On 12 April, a dry particle diameter of $75 \mathrm{~nm}$ was selected. The super-saturation in LACIS was varied from $0.35 \%$ to $0.9 \%$. On 14 April, a fixed super-saturation of $0.42 \%$ was selected while the dry particle diameter was varied from $70 \mathrm{~nm}$ to $160 \mathrm{~nm}$ in steps of $10 \mathrm{~nm}$.

In addition to measuring the size of the droplets at the LACIS outlet, the number fraction of the activated particles was determined. For this, the particle number concentration of the dry aerosol was measured with a CPC, after the DMA (see Fig. 1). The droplet number concentration of the activated particles was determined with the optical particle spectrometer at the LACIS outlet. The droplets originating from particles with a single charge can be distinguished from the droplets originating from doubly charged particles (see Fig. 3). For our evaluation, the number of activated singly charged particles was determined and was used to derive the fraction of the activated particles.

The results for the measurements on 12 April are given in Figs. 6 and 7. Figure 6 shows the size of the grown droplets at the LACIS outlet. Signals for singly and doubly charged particles could be distinguished and were evaluated separately. Doubly charged particles (here with a dry mobility diameter of $111 \mathrm{~nm}$ ) were found to activate for all super-saturations used during the measurements. Activated singly charged particles clearly could be detected for super-saturations above $0.5 \%$. However, at a super-saturation of $0.42 \%$ and below, there was no signal from the singly charged particles, i.e. their grown size was below the detection limit of $250 \mathrm{~nm}$ of the optical particle spectrometer, indicated by the hatched area in Fig. 6. The sharp decrease in grown size from $0.5 \%$ to $0.42 \%$ signifies the transition across the critical supersaturation. With this, the critical super-saturation for the ac-

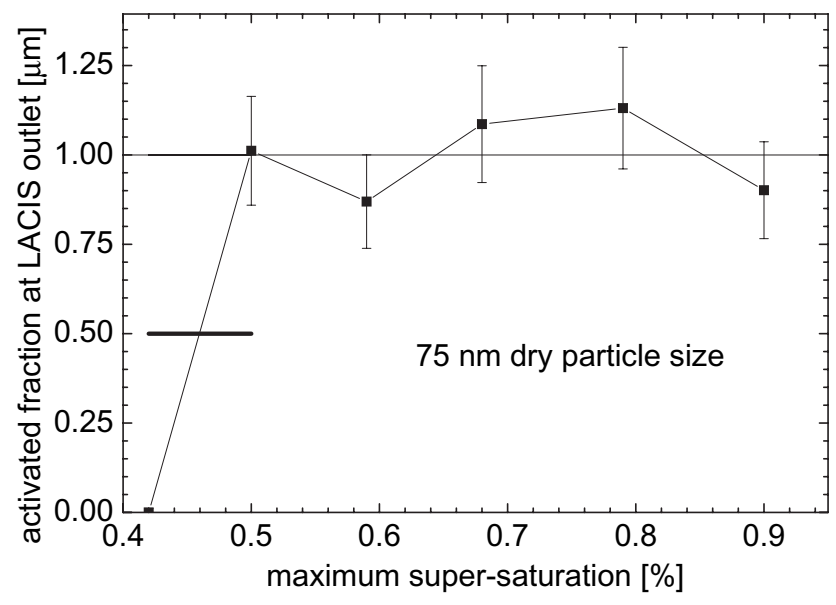

Fig. 7. Measured activated fraction (normalized to one) for the same measurements as shown in Fig. 6. The black bar indicates the uncertainty of the measurement with respect to the super-saturation.

tivation of the measured atmospheric particles with a dry diameter of $75 \mathrm{~nm}$ was found to be $0.46 \%+/-0.04 \%$.

Figure 7 shows the number fraction of the activated particles. At a super-saturation of $0.42 \%$ and below, none of the singly charged particles was activated. Already at $0.5 \%$ super-saturation, the average value for the final fraction of activated particles was reached. The increase in the activated fraction occurred over a narrow maximum super-saturation interval, due to the elimination of doubly charged particles from the fraction of activated particles. From the activated fraction, the same critical super-saturation as derived from the measurement of the grown sizes, i.e. of $0.46 \%+/-0.04 \%$, is obtained.

For the second day of measurements, the super-saturation was kept at a value of $0.42 \%$, whereas the dry particle diameter was varied. Again, the measurements of the grown size of the particles/droplets as well as the activated fraction were used to determine the critical dry particle diameter for the activation. Figures 8 and 9 show the respective measured values. Again, grown size and activated fraction both yield the same results, with $85 \mathrm{~nm}+/-5 \mathrm{~nm}$ as the derived critical diameter for the urban atmospheric particles at $0.42 \%$ supersaturation. The results of both days of measurements are given in Table 1.

Measurements on critical super-saturations for sizesegregated urban aerosol particles are rare, but those existing give values which are comparable to those found in the present study. Brechtel and Kreidenweis (2000b) measured critical super-saturations of size segregated atmospheric aerosol particles outside their laboratory at Fort Collins, Colorado. Measured values were $0.50 \%$ and $0.51 \%$ for particle sizes of 68.5 and $85 \mathrm{~nm}$, respectively. Critical super-saturations given in Hudson and Da (1996) for measurements in Reno, Nevada, are $0.3 \%$ and $0.23 \%$ for particle 
Table 1. Measured critical diameters and critical super-saturations for urban atmospheric aerosol particles. Uncertainties are only given for the values derived from LACIS measurements.

\begin{tabular}{lcc}
\hline & critical diameter & critical super-saturation \\
\hline 12 April 2005 & $75 \mathrm{~nm}$ & $0.46+/-0.04 \%$ \\
14 April 2005 & $85+/-5 \mathrm{~nm}$ & $0.42 \%$ \\
\hline
\end{tabular}

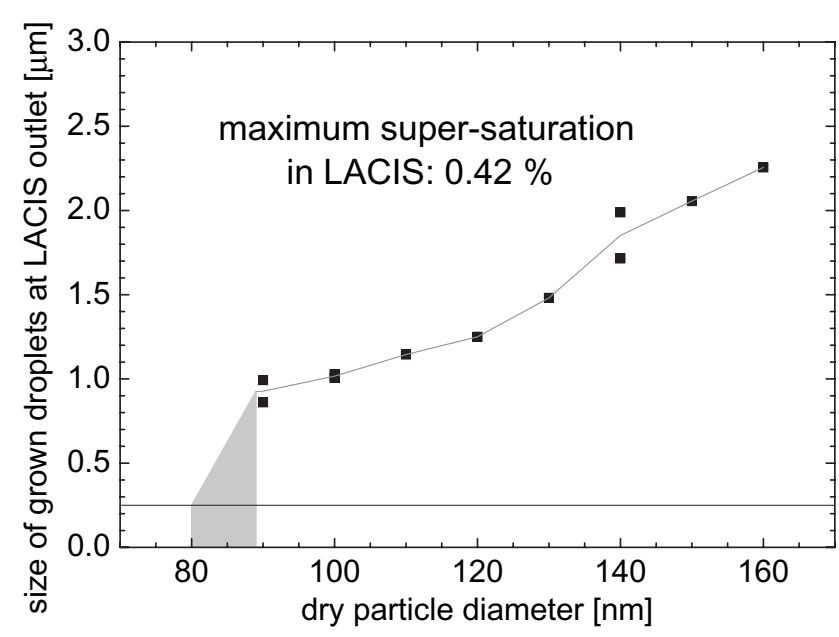

Fig. 8. The size of the grown droplets at the LACIS outlet, determined for different dry sizes of the urban atmospheric aerosol particles at a super-saturation in LACIS of $0.42 \%$.

sizes of 60 and $100 \mathrm{~nm}$, and for measurements done in Sacramento, California, are $0.5 \%$ and $0.45 \%$ for 60 and $100 \mathrm{~nm}$, respectively. Recently, Dusek et al. (2006) obtained a critical diameter of $83 \mathrm{~nm}$ at a super-saturation of $0.4 \%$ for an air mass that recently had passed over the city of Frankfurt, Germany.

Thus, the values measured in this study are in the same range than earlier measurements of the $\mathrm{CCN}$ behavior of urban atmospheric aerosol particles. This clearly shows the capability of LACIS to measure activation of atmospheric aerosol. A further lowering of the temperature steps of $\mathrm{T}_{\mathrm{wall}}$, which was $0.1 \mathrm{~K}$ for the measurements presented here, can further decrease the uncertainty of the measurement. A step width of $0.05 \mathrm{~K}$ is feasible (maybe even $0.02 \mathrm{~K}$ ) resulting in uncertainties of $+/-0.02 \%$ (or $+/-0.01 \%$, respectively).

\subsection{Hygroscopic growth}

Measurements of equilibrium diameters of the urban aerosol were done during the course of about $24 \mathrm{~h}$, on 9 and 10 March 2005. Measurements of equilibrium diameters with LACIS have been described in Wex et al. (2005). For this study, relative humidities used during the measurements were ad-

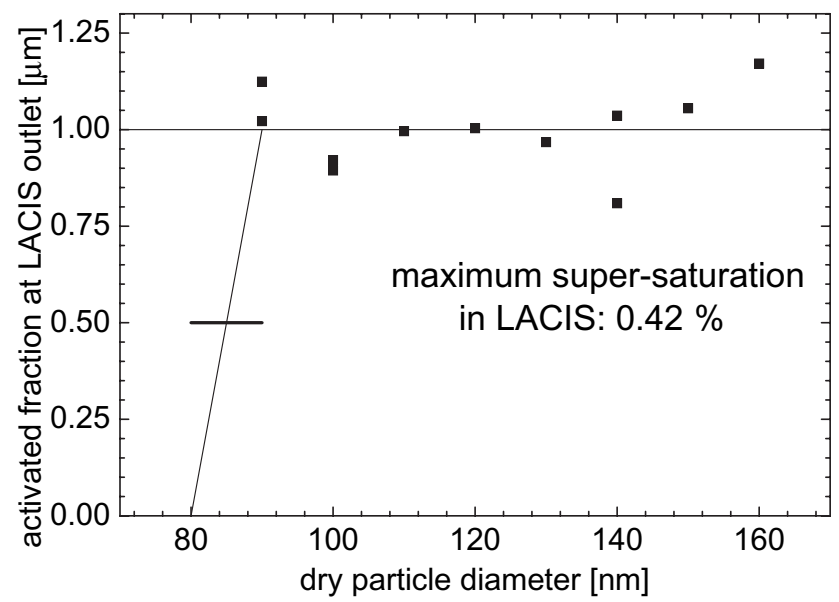

Fig. 9. Measured activated fraction (normalized to one), for the same measurements as shown in Fig. 8.

justed to 98 and $99 \%$, the particle diameters were 150, 300, and $350 \mathrm{~nm}$. Due to the detection limit of the optical particle spectrometer, only data for the more hygroscopic fraction of the aerosol were evaluated.

At the beginning, during, and at the end of the course of the measurements, the hygroscopic growth of both, $\mathrm{NaCl}$ and $\left(\mathrm{NH}_{4}\right)_{2} \mathrm{SO}_{4}$ particles of 150 and $300 \mathrm{~nm}$ was measured and compared to the hygroscopic growth predicted by Tang (1996) for $\mathrm{NaCl}$ and Tang and Munkelwitz (1994) for $\left(\mathrm{NH}_{4}\right)_{2} \mathrm{SO}_{4}$, to check the $R H$ in the flow tube. Due to a drift of two Pt-100 resistance thermometers that had not been noticed before, the $R H$ in the flow tube was found to be $97.8+/-0.1 \%$ and $98.7+/-0.1 \% R H$. These $R H$ s were confirmed when the Pt-100 resistance thermometers were calibrated after the measurements.

For the measurements of equilibrium diameters, the size of a grown particle at the LACIS outlet corresponds to a growth factor $g$, which is defined as the ratio of the equilibrium size of the grown particle $\left(d_{\text {droplet }}\right)$ and the dry mass equivalent diameter of the particle $\left(d_{\text {dry }}\right): g=d_{\text {droplet }} / d_{\text {dry }}$.

Measured growth factors of atmospheric aerosol particles for the different $R H$ s and the different dry particle sizes are given in Figs. 10 and 11. Also shown are the growth factors for ammonium sulfate particles at the respective sizes and $R H$ s, according to Tang and Munkelwitz (1994). Additionally, Table 2 lists the different average measured values of $g$, together with the growth factors of ammonium sulfate for the respective particles (shown in parenthesis). Also included in Table 2 are the soluble volume fractions $\epsilon$ for the measured data (Pitchford and McMurry, 1994), referenced to pure ammonium sulfate as the soluble compound.

At both $R H$ s the $150 \mathrm{~nm}$ particles grow less, compared to ammonium sulfate, than the 300 and $350 \mathrm{~nm}$ particles. Values of $g$ for the $150 \mathrm{~nm}$ particles are only $85 \%$ of $g$ for $\left(\mathrm{NH}_{4}\right)_{2} \mathrm{SO}_{4}$, whereas for 300 and $350 \mathrm{~nm}$ the measured 
Table 2. Average measured values of $g$, together with the respective $g$ of ammonium sulfate (given in parenthesis), and the soluble volume fractions $\epsilon$ based on ammonium sulfate as the soluble compound.

\begin{tabular}{cccc}
\hline & $150 \mathrm{~nm}$ & $300 \mathrm{~nm}$ & $350 \mathrm{~nm}$ \\
\hline $97.8 \% R H$ & & & \\
$\mathrm{~g}$ & $2.13(2.52)$ & $2.49(2.62)$ & $2.51(2.63)$ \\
$\epsilon$ & 0.58 & 0.85 & 0.87
\end{tabular}

\begin{tabular}{cccc}
$98.7 \% R H$ & & & \\
$\mathrm{~g}$ & $2.51(2.92)$ & $2.92(3.08)$ & $2.92(3.11)$ \\
$\epsilon$ & 0.62 & 0.85 & 0.82 \\
\hline
\end{tabular}

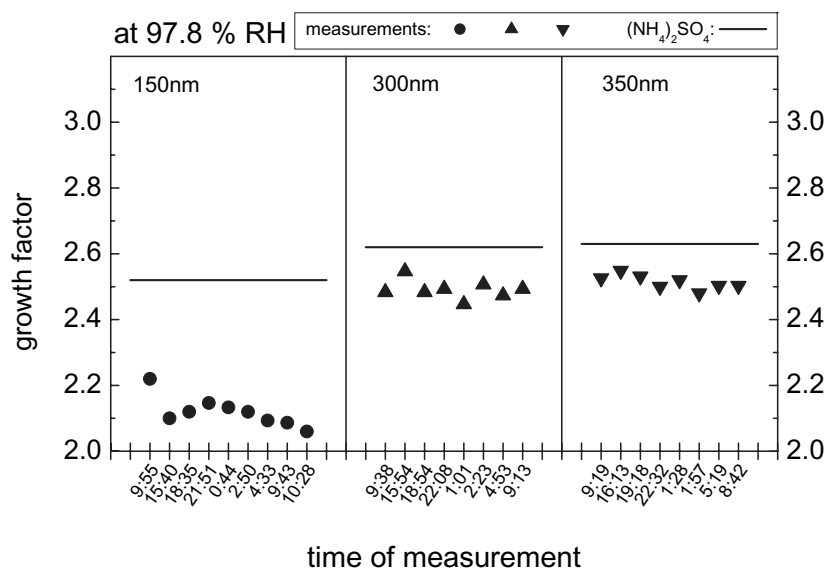

Fig. 10. Measured growth factors for urban atmospheric aerosol particles on 9 and 10 March 2005, with dry diameters of $150 \mathrm{~nm}$, 300 , and $350 \mathrm{~nm}$, at $97.8 \% \mathrm{RH}$. Also shown are growth factors for respective ammonium sulfate particles, based on Tang and Munkelwitz (1994).

growth is $95 \%$ of that of $\left(\mathrm{NH}_{4}\right)_{2} \mathrm{SO}_{4}$. This can also be seen in the values for $\epsilon$, which are around 0.60 for the $150 \mathrm{~nm}$ particles and around 0.85 for the 300 and $350 \mathrm{~nm}$ particles.

Particles with dry diameters of 300 and $350 \mathrm{~nm}$ show similar values for $g$ and $\epsilon$.

These findings indicate different chemical compositions for the $150 \mathrm{~nm}$ particles, compared to the larger ones. The larger particles may have been processed in clouds longer or more often, adding soluble substances such as $\left(\mathrm{NH}_{4}\right)_{2} \mathrm{SO}_{4}$, and thereby increasing their hygroscopic growth.

Our results support earlier measurements at $90 \% R H$ for continental aerosol (e.g., Svenningsson et al., 1992, 1997; Pitchford and McMurry, 1994; Swietlicki et al., 1999; Busch et al., 2002) where $g$ measured for atmospheric aerosol increased relative to $g$ of $\left(\mathrm{NH}_{4}\right)_{2} \mathrm{SO}_{4}$ for increasing particle size. Values for $\epsilon$ for the more hygroscopic fraction, taken or derived from these publications, range from 0.46 to 0.69

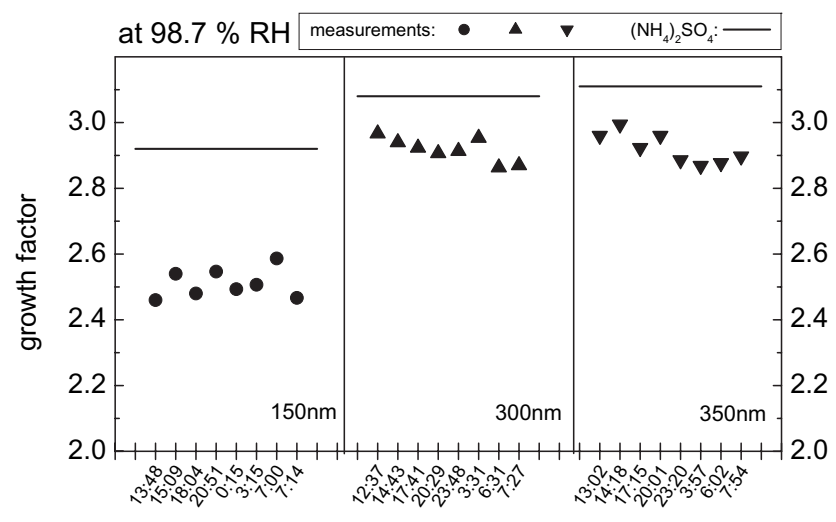

time of measurement

Fig. 11. Similar to Fig. 10, but for $98.7 \% R H$.

for particles with a dry diameter of $150 \mathrm{~nm}$. The results from our measurements for the $150 \mathrm{~nm}$ particles are well within this range, although they were measured at larger $R H \mathrm{~s}$. Publications of growth factors for particles with 300 and $350 \mathrm{~nm}$ are not available, but Zhang et al. (1993) found $g$ of 1.63 for $400 \mathrm{~nm}$ particles of urban atmospheric aerosol at $90 \% \mathrm{RH}$, which gives $\epsilon$ of 0.81 , based on $\left(\mathrm{NH}_{4}\right)_{2} \mathrm{SO}_{4}$ as the assumed soluble substance, which also agrees with our results.

In the past, attempts have been made to derive the number of cloud condensation nuclei (CCN) of an aerosol from measurements of hygroscopic properties (e.g., Covert et al., 1998; Dusek et al., 2003). Generally, the derived number of $\mathrm{CCN}$ overestimates the number of $\mathrm{CCN}$ measured. It has been postulated, that this deviation is based on different hygroscopic growth behavior of the atmospheric aerosol particles at $90 \% R H$ compared to larger $R H$ s or to conditions just below their critical super-saturation. This effect was attributed to organic compounds which might act as surface active films or which might dissolve only at larger $\mathrm{RH}$ s. However, measurements of hygroscopic growth of atmospheric aerosol particles up to date could not be performed at $99 \%$ $\mathrm{RH}$ and these measurements are needed to solve the discrepancy described above.

The results we present here from LACIS measurements at sub-saturation do not comprise a long measurement period and thus are not a statistically relevant data-set, but they show the possibility of measuring the hygroscopic growth factors of atmospheric aerosol particles with LACIS. However, a CCN closure was not performed, since the data on hygroscopic growth and on the activation of the atmospheric aerosol particles were not measured at the same time. A field-version of LACIS is planned which will be optimized for the special needs for this kind of measurements. Running LACIS-field at high $R H \mathrm{~s}$ alternating with its use as a CCN detector, together with a Hygroscopic Tandem Differential Mobility Analyzer (HTDMA), measuring the hygroscopic 
growth at lower $R H$ s (e.g. 90\%), can give valuable insights in hygroscopic properties of the atmospheric aerosol and in its interaction with cloud droplets.

\section{Conclusions}

The Leipzig Aerosol Cloud Interaction Simulator (LACIS) was calibrated for use as a $\mathrm{CCN}$ detector. Particles of ammonium sulfate and sodium chloride were used to derive the relation between the LACIS wall temperature and its effective super-saturation. The calibration was double-checked successfully, with the results from the two different salts being in agreement with each other.

As a test for the calibration and a first atmospheric application, the activation of atmospheric aerosol particles was measured. Additionally, to show the applicability of LACIS for atmospheric measurements in general, measurements were also done on the hygroscopic growth of atmospheric aerosol particles.

For measurements at super-saturation, two different ways of deriving critical super-saturation and critical dry diameters were used (the activated fraction and the size of activated particles). Both methods yield the same results. Measurements were performed on two different days, yielding a critical super-saturation of $0.46+/-0.04 \%$ for particles with $75 \mathrm{~nm}$ dry diameter on the first day, and a critical diameter of $85 \mathrm{~nm}+/-5 \mathrm{~nm}$ for the super-saturation of $0.42 \%$ for the second day of measurements. These values are in agreement with values reported in literature.

Measurements of the hygroscopic growth for $98 \%$ to $99 \%$ $\mathrm{RH}$ showed increasing growth factors with increasing particle size (from $150 \mathrm{~nm}$ to 300 and $350 \mathrm{~nm}$ ), getting closest to the growth factors of ammonium sulfate for particles with dry sizes of 300 and $350 \mathrm{~nm}$. Measured growth factors and soluble volume fractions are in agreement with values reported in literature.

Summarizing it can be stated that LACIS was calibrated successfully for its use as a CCN detector, and that its applicability for measuring activation and hygroscopic growth of atmospheric aerosol particles has been shown.

Edited by: U. Lohmann

\section{References}

Brechtel, F. J. and Kreidenweis, S. M.: Predicting particle critical supersaturation from hygroscopic growth measurements in the humidified TDMA. Part I: Theory and sensitivity studies, J. Atmos. Sci., 57, 1854-1871, 2000a.

Brechtel, F. J. and Kreidenweis, S. M.: Predicting particle critical supersaturation from hygroscopic growth measurements in the humidified TDMA. Part II: Laboratory and ambient studies, J. Atmos. Sci., 57, 1872-1887, 2000b.
Busch, B., Kandler, K., Schütz, L., and Neusüß, C.: Hygroscopic properties and water-soluble volume fraction of atmospheric particles in the diameter range from $50 \mathrm{~nm}$ to $3.8 \mu \mathrm{m}$ during LACE 98, J. Geophys. Res., 107(D21), 8119, doi:10.1029/2000JD000228, 2002.

Covert, D. S., Gras, J. L., Wiedensohler, A., and Stratmann, F.: Comparison of directly measured $\mathrm{CCN}$ with $\mathrm{CCN}$ modeled from the number-size distribution in the marine boundary layer during ACE1 at Cape Grim, Tasmania, J. Geophys. Res., 103, $16597-$ 16608, 1998.

Dusek, U., Covert, D. S., Wiedensohler, A., Neusüß, C., Weise, D., and Chantrell, W.: Cloud condensation nuclei spectra derived from size distributions and hygroscopic properties of the aerosol in coastal southwest Portugal during ACE-2, Tellus, 55, 35-53, 2003.

Dusek, U., Frank, G. P., Hildebrandt, L., Curtius, J., Schneider, J., Walter, S., Chand, D., Drewnick, F., Hings, S., Jung, D., Borrmann, S., and Andreae, M. O.: Size matters more than chemistry for cloud-nucleating ability of aerosol particles, Science, 312, 1375-1378, 2006.

FLUENT: 6 users guide, Tech. rep., Fluent Inc., 2003.

Hudson, J. G. and Da, X.: Volatility and size of cloud condensation nuclei, J. Geophys. Res., 101, 4435-4442, 1996.

Hudson, J. G., Garrett, T. J., Hobbs, P. V., Strader, S. R., Xie, Y., and Yum, S. S.: Cloud condensation nuclei and ship tracks, J. Atmos. Sci., 57, 2696-2706, 2000.

IPCC: Houghton, J. T., Ding, Y., Griggs, D. J., Noguer, M., van der Linden, P. J., Dai, X., Maskell, K., and Johnson, C. A.: Climate change 2001: The scientific basis, Cambridge Univ. Press, Cambridge, 2001.

Kelly, W. P. and McMurry, P. H.: Measurement of particle density by inertial classification of differential mobility analyzergenerated monodisperse aerosols, Aerosol Sci. Technol., 17, 199-212, 1992.

Kiselev, A., Wex, H., Stratmann, F., Nadeev, A., and Karpushenko, D.: White-light optical particle spectrometer for in situ measurement of condensational growth of aerosol particles, Appl. Opt., 44, 4693-4701, 2005.

Knutson, E. O. and Whitby, K. T.: Aerosol classification by electric mobility: Apparatus, theory and applications, J. Aerosol Sci., 6, 75-76, 1975.

Koehler, K. A., Kreidenweis, S. M., DeMott, P. J., Prenni, A. J., Carrico, C. M., Ervens, B., and Feingold, G.: Water activity and activation diameters from hygroscopicity data - Part II: Application to organic species, Atmos. Chem. Phys., 6, 795-809, 2006, http://www.atmos-chem-phys.net/6/795/2006/.

Kreidenweis, S. M., Koehler, K. A., DeMott, P., Prenni, A. J., Carrico, C. M., and Ervens, B.: Water activity and activation diameters from hygroscopicity data - Part I: Theory and application to inorganic salts, Atmos. Chem. Phys., 5, 1357-1370, 2005, http://www.atmos-chem-phys.net/5/1357/2005/.

Kumar, P. P., Broekhuizen, K., and Abbatt, J. P. D.: Organic acids as cloud condensation nuclei: Laboratory studies of highly soluble and insoluble species, Atmos. Chem. Phys., 3, 509-520, 2003, http://www.atmos-chem-phys.net/3/509/2003/.

Low, R. D. H.: A generalized equation for the solution effect in droplet growth, J. Atmos. Sci., 26, 608-611, 1969.

Massling, A., Wiedensohler, A., Busch, B., Neusüß, C., Quinn, P., Bates, T., and Covert, D. C.: Hygroscopic properties of different 
aerosol types over the Atlantic and Indian Ocean, Atmos. Chem. Phys., 3, 1377-1397, 2003,

http://www.atmos-chem-phys.net/3/1377/2003/.

Pitchford, M. and McMurry, P. H.: Relationship between measured water vapor growth and chemistry of atmospheric aerosol for Grand Canyon, Arizona, in winter 1990, Atmos. Environ., 28, 827-839, 1994.

Raymond, T. M. and Pandis, S. N.: Cloud activaton of single-component organic aerosol particles, J. Geophys. Res., 107(D24), 4787, doi:10.1029/2002JD002159, 2002.

Snider, J. R. and Brenguier, J.-L.: Cloud condensation nuclei and cloud droplet measurements during ACE-2, Tellus, 52, 828-842, 2000 .

Stratmann, F., Kiselev, A., Wurzler, S., Wendisch, M., Heintzenberg, J., Charlson, R. J., Diehl, K., Wex, H., and Schmidt, S.: Laboratory studies and numerical simulations of cloud droplet formation under realistic super-saturation conditions, J. Atmos. Oceanic Technol., 21, 876-887, 2004.

Svenningsson, B., Hansson, H.-C., Martinsson, B., Wiedensohler, A., Swietlicki, E., Cederfelt, S.-I., Wendisch, M., Bower, K. N., Choularton, T. W., and Colvile, R. N.: Cloud droplet nucleation scavenging in relation to the size and hygroscopic behaviour of aerosol particles, Atmos. Environ., 31, 2463-2475, 1997.

Svenningsson, I. B., Hansson, H.-C., Wiedensohler, A., Ogren, J. A., Noone, K. J., and Hallberg, A.: Hygroscopic growth of aerosol particles in the Po Valley, Tellus, 44B, 556-569, 1992.
Swietlicki, E., Zhou, J., Berg, O. H., Martinsson, B. G., Frank, G., Cederfeld, S.-I., Dusek, U., Berner, A., Birmili, W., Wiedensohler, A., Yuskiewicz, B., and Bower, K.-N.: A closure study of sub-micrometer aerosol particle hygroscopic behaviour, Atmos. Res., 50, 205-240, 1999.

Tang, I. N. and Munkelwitz, H. R.: Water activities, densities and refractive indices of aqueous sulfates and sodium nitrate droplets of atmospheric importance, J. Geophys. Res., 99, 18 801-18 808, 1994.

Tang, I. N.: Chemical and size effects of hygroscopic aerosols on light scattering coefficients, J. Geophys. Res., 101, 19245$19250,1996$.

Wex, H., Kiselev, A., Stratmann, F., Zoboki, J., and Brechtel, F.: Measured and modeled equilibrium sizes of $\mathrm{NaCl}$ and $\left(\mathrm{NH}_{4}\right)_{2} \mathrm{SO}_{4}$ particles at relative humidities up to $99.1 \%$, J. Geophys. Res., 110(D21), 8122, doi:10.1029/2004JD005507, 2005.

Wilck, M., Stratmann, F., and Whitby, E. R.: A fine particle model for Fluent: Description and application, proceedings of 6th International Aerosol Conference, 69-70, Taipei, Taiwan, 2002.

Zhang, X. Q., McMurry, P. H., Hering, S. V., and Casuccio, G. S.: Mixing characteristics and water content of submicron aerosols measured in Los Angeles and at the Grand Canyon, Atmos. Environ., 27A, 1593-1607, 1993. 